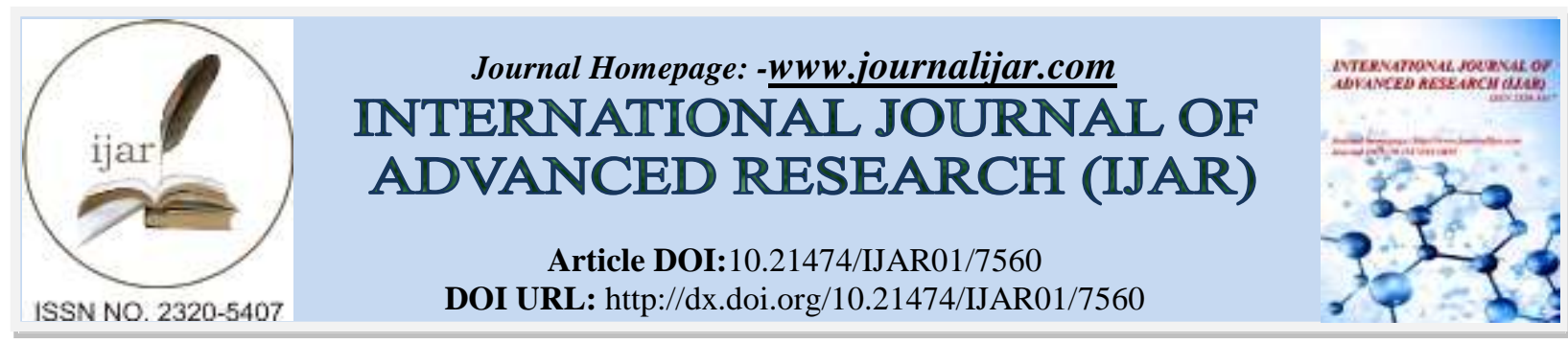

RESEARCH ARTICLE

\title{
RESEARCH AND APPLICATION OF LINKAGE MODEL OF NATURAL GAS PRICE.
}

Guangshuai Zhou, Jian Wang.

School of Mathematics and Statistics, Shandong University of Technology, China.

\section{Manuscript Info}

Manuscript History

Received: 14 June 2018

Final Accepted: 16 July 2018

Published: August 2018

Keywords:-

Natural gas price;

Alternative energy price;

Linkage model.

\section{Abstract}

The linkage models of natural gas price include static and dynamic pricing model, equivalent calorific value pricing model, which are based on the cost-plus method and net market value method respectively. The paper used the model to investigate Chinese natural gas price from October 2010 to April 2014. The results of empirical analysis showed that the real price of natural gas was lower than the price calculated by equivalent calorific value pricing model.

Copy Right, IJAR, 2018,. All rights reserved.

\section{Introduction:-}

Natural gas price has become a hot issue in the field of energy economics and has received widespread concern by researchers, under the background of widespread gas shortages last winter in China. Natural gas price plays an important role in gas market, and it is seen that the research on linkage model of natural gas price is very important.

\section{Methods And Models:-}

A. Cost-plus method--static \& dynamic pricing model:-

Static pricing mode ${ }^{[1]}$ : When the time of capital investment and recovery cannot be predicted the basic ex-factory price of natural gas can be written as $\mathrm{P}_{0 \mathrm{~S}}$.

$$
P_{0 S}=\frac{C}{R^{\prime}} \times \frac{1}{1-R^{\prime \prime}} \times\left(1+R^{\prime \prime \prime}\right)
$$

Where $\mathrm{C}$ is the cost of gas production and $R^{\prime}$ is the commodity rate of natural gas. $R^{\prime \prime}$ is composite tax rate and $R^{\prime \prime \prime}$ is rate of return.

Dynamic pricing model ${ }^{[1]}$ : The dynamic pricing model is based on the static pricing model and take the factor of time into account. The basic ex-factory price determined by the dynamic pricing method is written as $P_{O D}$.

$P_{O D}$ is determined by

$$
\sum_{t=1}^{n}(C I-C O)_{t}(1+I R R)^{-t}>0(2)
$$

Where $\mathrm{t}=1,2, \cdots, \mathrm{t}_{0}-1, \mathrm{t}_{0}, \mathrm{t}_{0}+1, \cdots, \mathrm{n}$, and $\mathrm{n}$ is business life cycle. CI is cash inflows and CO is cash outflows. IRR means internal rate of return. The dynamic pricing model determine the price of natural gas in accordance with the principle of "guarantee capital and profitability". 


\section{B. Net Market Value Method--equivalent calorific value pricing model:-}

The basic ex-factory price of natural gas determined by equivalent calorific value pricing model ${ }^{[2]}$ can be expressed as follows:

$$
\mathrm{P}_{0 \mathrm{E}}=\sum_{\mathrm{i}=1}^{\mathrm{n}} \mathrm{W}_{\mathrm{i}} \mathrm{A}_{\mathrm{it}_{0}} \mathrm{R}_{\mathrm{i}}
$$

Where i take on the value $1,2, \cdots, \mathrm{n}$, representing alternative energies $1,2, \cdots, \mathrm{n}$ respectively, such as coal, petroleum, electricity, etc. $W_{i}$ is the weight of $i$-th alternative energy.

$$
\begin{gathered}
\mathrm{W}_{\mathrm{i}}=\frac{\sum_{\mathrm{t}=\mathrm{t}_{0}-\mathrm{m}}^{\mathrm{t}_{0}-1} \mathrm{Q}_{\mathrm{it}}}{\sum_{\mathrm{i}=1}^{\mathrm{k}} \sum_{\mathrm{t}=\mathrm{t}_{0}-\mathrm{m}}^{\mathrm{t}_{0}-1} \mathrm{Q}_{\mathrm{it}}}(4) \\
\sum_{\mathrm{i}=1}^{\mathrm{k}} \mathrm{W}_{\mathrm{i}}=1(5)
\end{gathered}
$$

Where $Q_{i t}$ is the consumption of the $\mathrm{i}$-th alternative energy in t period, $A_{i t_{0}}$ is the moving average price of the first $\mathrm{m}$ phases of the type $i$ alternative energy in the $t_{0}$ period (current research period).

$$
\mathrm{A}_{\mathrm{it}_{0}}=\frac{1}{\mathrm{~m}} \sum_{\mathrm{t}=\mathrm{t}_{0}-\mathrm{m}}^{\mathrm{t}_{0}-1} \mathrm{~A}_{\mathrm{it}}(6)
$$

Where $A_{i t}$ is the price of the $i$-th type of alternative energy at the $t$ period. $R_{i}$ is the ratio of the calorific value of the $i$-th type of alternative energy and natural gas. $t=t_{0}-m, t_{0}-m+1, \cdots, t_{0}-1 . t_{0}>m$. Indicates $m$ periods before $t_{0}$ stage, $m$ is usually 3 or 5 .

\section{Improvement: 'Cost -Plus' and 'Net Market Value' Mixed Pricing model:-}

Some researchers pointed out that the dynamic pricing model is suitable for the initial stage of natural gas market, which the output of gas cannot meet the demand of consumer. And better to take the equivalent calorific value pricing model in mature market.

In order to reflect the gradual maturity of the developing process of the gas market, the mixed pricing model ${ }^{[2]}$ is proposed, $\mathrm{P}_{0}$ combines the weighted average of $\mathrm{P}_{0 \mathrm{D}}$ and $\mathrm{P}_{0 \mathrm{E}}$.

$$
\mathrm{P}_{0}=\alpha \mathrm{P}_{0 \mathrm{D}}+\beta \mathrm{P}_{0 \mathrm{E}}
$$

Where $\alpha+\beta=1(0 \leq \alpha, \beta \leq 1)$. In the initial stage of the natural gas market, $\alpha$ has a greater weight and $\beta$ has a smaller weight. While the market matures gradually, $\alpha$ has a smaller weight.

\section{$D$. Adjustment model of natural gas ex-factory price:-}

The ex-factory price of natural gas cannot be maintained for a long time. Therefore the adjustment model of natural gas priceneed to be considered.

(1) Product form ${ }^{[1]}$ :

$$
P_{t}=P_{0} \times\left(\alpha_{1} \times \frac{A_{1 t}}{A_{01}}+\alpha_{2} \times \frac{A_{2 t}}{A_{02}}+\cdots+\alpha_{m} \frac{A_{m t}}{A_{0 m}}\right)(8)
$$

(2) Addition form ${ }^{[1]}$ :

$$
P_{t}=P_{0}+\alpha_{1}\left(A_{1 t}-A_{01}\right)+\alpha_{2}\left(A_{2 t}-A_{02}\right)+\cdots+\alpha_{m}\left(A_{m t}-A_{0 m}\right)(9)
$$

Where $P_{t}$ is natural gas price in adjustment period, and $P_{0}$ is basic ex-factory price of natural gas. $A_{1 t}$ is the price of the $i$-th alternative energies in adjustment period price. $\alpha_{i}$ is influential weight of the $i$-th alternative energies. $m$ is the number of alternative energy.

\section{Empirical Analysis:-}

In this part, the paper compare the real price of natural gas price with the theoretical price calculated by equivalent calorific value pricing model of China from October 2010 to April 2014. For natural gas price, we use the average upstream ex-factory price of the three major natural gas producers in China, and the alternative energies are No.93 gasoline $^{[3]}$, coal $^{[3]}$ and electricity. The electricity price is obtained by calculating according to the formula $(10)^{[4]}$. And other data such as proportion of energy consumption are obtained from the Statistical Yearbook of the National Bureau of Statistics of China ${ }^{[5]}$. 


$$
P_{E L E}=0.3043 e^{0.0918(t-2010)},(t \geq 2010)(10)
$$

According to the equivalent calorific value pricing model:

$$
P_{0 E}=\sum_{i=1}^{3} W_{i} A_{i t_{0}} R_{i}(11)
$$

Fig.10 presents the theoretical price of natural gas. Comparing the real price and theoretical price of natural gas, it can be seen from Fig.11 that, except for a few months, the real price of natural gas is lower than the theoretical price.

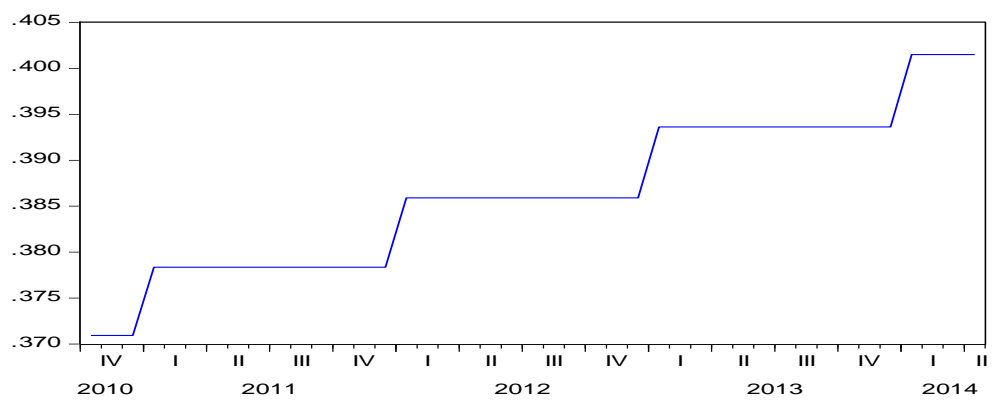

Fig.6. Electricity price $(¥ / \mathrm{kWh})$

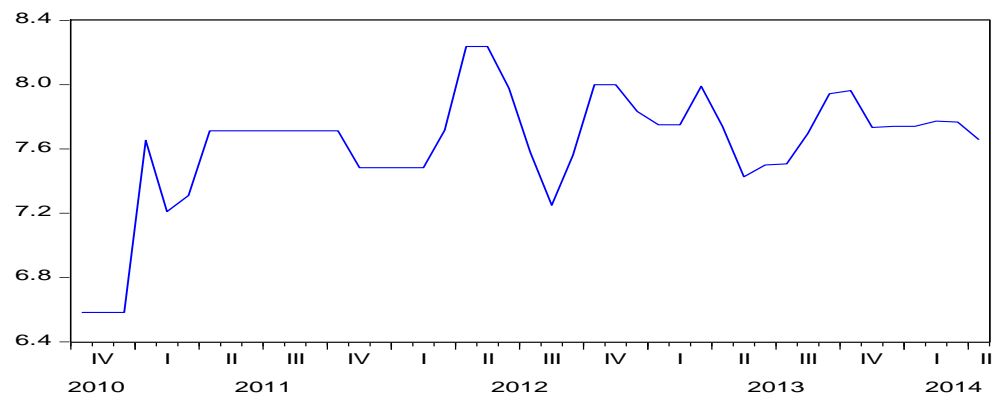

Fig.7.No. 93 gasoline price $(¥ / \mathrm{L})$

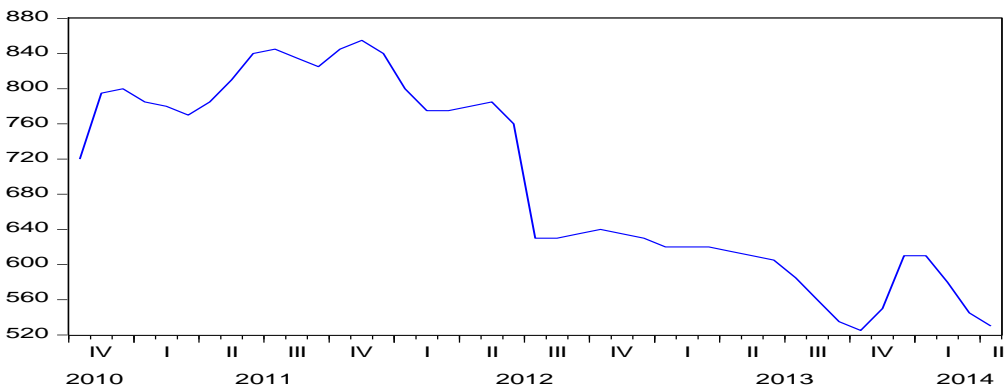

Fig.8. Price of thermal coal ( $¥ /$ ton)

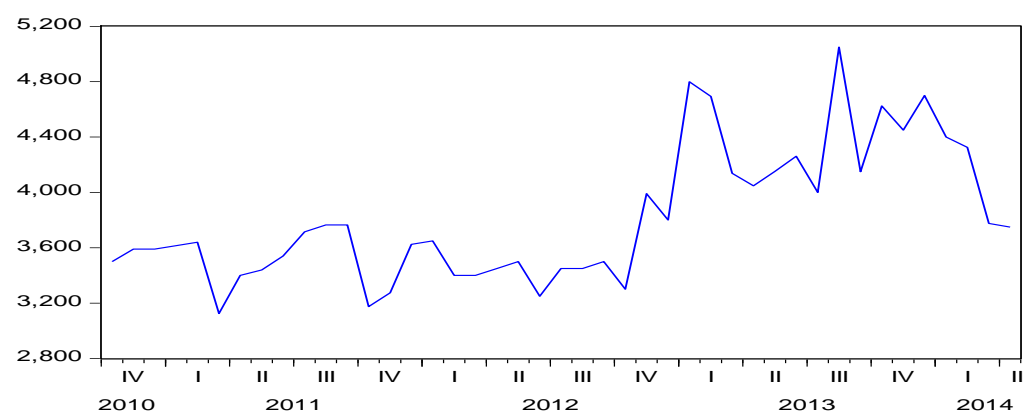

Fig.9. Real price of natural gas ( $¥ /$ ton) 

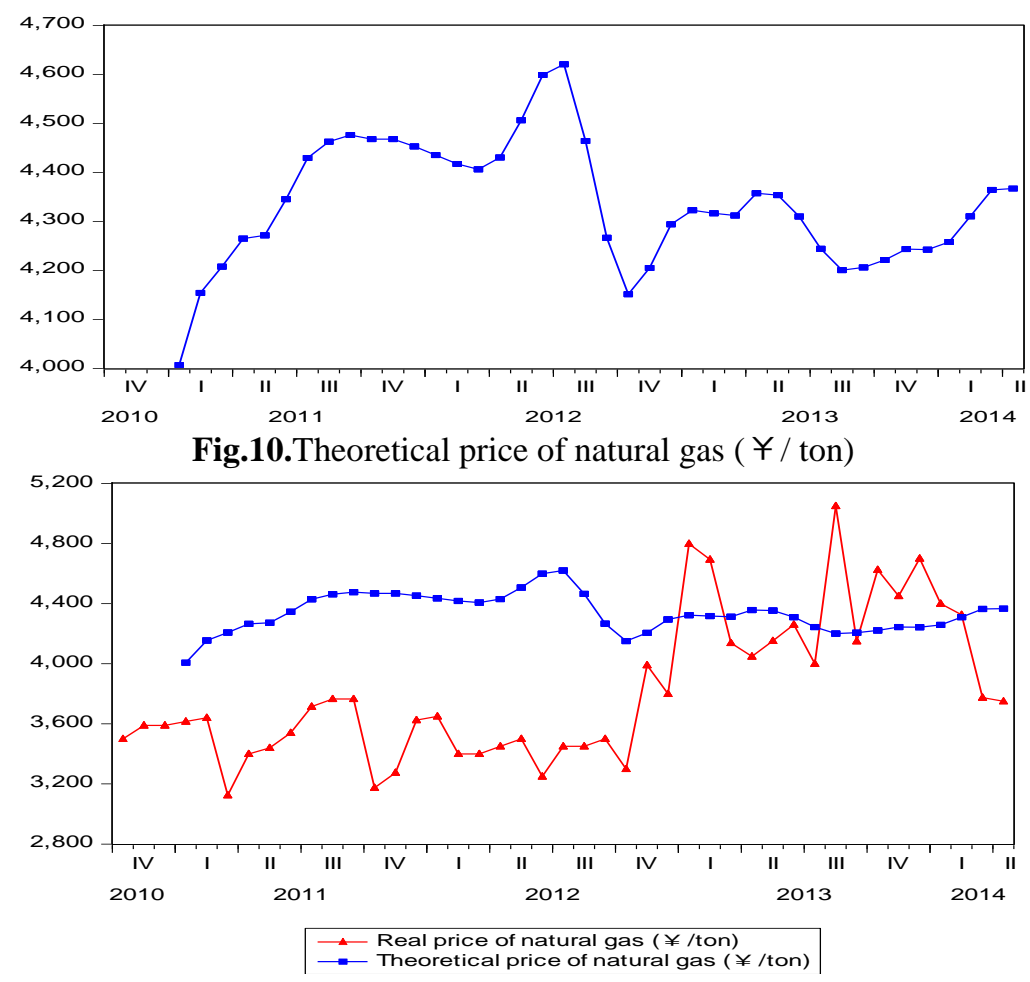

Fig.11.

\section{Conclusions:-}

The static pricing model based on cost-plus method does not take into account the factor of time while the dynamic pricing model does. Both the two models are suitable for initial stage of gas market.

The equivalent calorific value pricing model based on net market value method establish the linkage with the price of alternative energies, which is suitable for mature gas market. Improved model combine the dynamic pricing model and equivalent calorific value pricing model by the degree of maturity of gas market.

The empirical analysis on Chinese natural gas market discloses that the real gas price determined by cost-plus method is lower than the theoretical price calculated by equivalent calorific value pricing model in most sample period.

\section{References:-}

1. Peng, Y., 2006.Research on Natural Gas Pricing Formula. Master dissertation of Southwest Petroleum University, China.

2. Wu, J.L. and Yan, M., 2009. Study on the formula of natural gas ex-factory price.Journal of Natural Gas Technology Macro Research, 3 (1):7-9.

3. Liang, L. Analysis on the relationship between main Energy Price and its influencing factors in China. Master dissertation of Jiangsu University, China.

4. Li, T. and Wang, X.Z., 2006. The price of natural gas from the perspective of alternative energy. Journal of Petrochemical Technology and economy, 22 (6):10-13.

5. http://edudata.drcnet.com.cn/web/OLAPQuery.aspx?databasename=energy\&cubeName=BPNPrice \&channel=1 $28 \&$ nodeId=482\&uid=9958061905. 